\title{
Heats of Formation of Triplet Ethylene, Ethylidene, and Acetylene ${ }^{\dagger}$
}

\author{
Minh Tho Nguyen, \\ Department of Chemistry, The University of Alabama, Shelby Hall, Tuscaloosa, Alabama 35487-0339, \\ Department of Chemistry, University of Leuven, B-3001 Leuven, Belgium, and Chemical Sciences Division, \\ Lawrence Berkeley National Laboratory, and Department of Chemistry, University of California, Berkeley, \\ California 94720-1460
}

Received: June 19, 2007

\begin{abstract}
Heats of formation of the lowest triplet state of ethylene and the ground triplet state of ethylidene have been predicted by high level electronic structure calculations. Total atomization energies obtained from coupledcluster $\operatorname{CCSD}(\mathrm{T})$ energies extrapolated to the complete basis set limit using correlation consistent basis sets (CBS), plus additional corrections predict the following heats of formation in kcal/mol: $\Delta H_{\mathrm{f}}^{0}\left(\mathrm{C}_{2} \mathrm{H}_{4},{ }^{3} \mathrm{~A}_{1}\right)=$ 80.1 at $0 \mathrm{~K}$ and 78.5 at $298 \mathrm{~K}$, and $\Delta H_{\mathrm{f}}^{0}\left(\mathrm{CH}_{3} \mathrm{CH},{ }^{3} \mathrm{~A}^{\prime \prime}\right)=86.8$ at $0 \mathrm{~K}$ and 85.1 at $298 \mathrm{~K}$, with an error of less than $\pm 1.0 \mathrm{kcal} / \mathrm{mol}$. The vertical and adiabatic singlet-triplet separation energies of ethylene were calculated as $\Delta E_{\mathrm{S}-\mathrm{T} \text {,vert }}=104.1$ and $\Delta E_{\mathrm{S}-\mathrm{T} \text {,adia }}=65.8 \mathrm{kcal} / \mathrm{mol}$. These results are in excellent agreement with recent quantum Monte Carlo (DMC) values of $103.5 \pm 0.3$ and $66.4 \pm 0.3 \mathrm{kcal} / \mathrm{mol}$. Both sets of computational values differ from the experimental estimate of $58 \pm 3 \mathrm{kcal} / \mathrm{mol}$ for the adiabatic splitting. The computed singlet-triplet gap at $0 \mathrm{~K}$ for acetylene is $\Delta E_{\mathrm{S}-\mathrm{T} \text {,adia }}\left(\mathrm{C}_{2} \mathrm{H}_{2}\right)=90.5 \mathrm{kcal} / \mathrm{mol}$, which is in notable disagreement with the experimental value of $82.6 \mathrm{kcal} / \mathrm{mol}$. The heat of formation of the triplet is $\Delta H_{\mathrm{f}}^{0}\left(\mathrm{C}_{2} \mathrm{H}_{2},{ }^{3} \mathrm{~B}_{2}\right)=145.3$ $\mathrm{kcal} / \mathrm{mol}$. There is a systematic underestimation of the singlet-triplet gaps in recent photodecomposition experiments by $\sim 7$ to $8 \mathrm{kcal} / \mathrm{mol}$. For vinylidene, we predict $\Delta H_{\mathrm{f}}^{0}\left(\mathrm{H}_{2} \mathrm{CC},{ }^{1} \mathrm{~A}_{1}\right)=98.8 \mathrm{kcal} / \mathrm{mol}$ at $298 \mathrm{~K}$ (exptl. $100.3 \pm 4.0), \Delta H_{\mathrm{f}}^{0}\left(\mathrm{H}_{2} \mathrm{CC},{ }^{3} \mathrm{~B}_{2}\right)=146.2$ at $298 \mathrm{~K}$, and an energy gap $\Delta E_{\mathrm{S}-\mathrm{T}-\mathrm{adia}}\left(\mathrm{H}_{2} \mathrm{CC}\right)=47.7 \mathrm{kcal} /$ mol.
\end{abstract}

\section{Introduction}

The prediction of the energies of the excited states of small hydrocarbons $\mathrm{C}_{n} \mathrm{H}_{m}$ remains a challenging task for both experimental and theoretical chemists alike, even though this issue has been investigated extensively. After decades of research, the heat of formation $\left(\Delta H_{\mathrm{f}}\right)$ and the singlet-triplet gap $\left(\Delta E_{\mathrm{S}-\mathrm{T}}\right)$ of methylene have now been well established, ${ }^{1-3}$ and there is excellent agreement between experiment and theory (cf. ref 4 for a list of benchmark studies on $\mathrm{CH}_{2}$ ).

The agreement between theory and experiment is currently not as good for $\Delta E_{\mathrm{S}-\mathrm{T}}$ of acetylene. The singlet-triplet gap in acetylene has extensively been investigated by molecular orbital theory $^{5-8}$ and experiment. ${ }^{9}$ Suits and co-workers ${ }^{9}$ reported an experimental value of $T_{0}=\Delta E_{\mathrm{S}-\mathrm{T} \text {,adia }}\left(\mathrm{C}_{2} \mathrm{H}_{2}\right)=82.6 \mathrm{kcal} / \mathrm{mol}$ $\left(28900 \mathrm{~cm}^{-1}\right)$ for triplet acetylene $\mathrm{C}_{2} \mathrm{H}_{2}\left(\tilde{\mathrm{a}}^{3} \mathrm{~B}_{2}\right)$ evaluated by photodissociation of the vinyl radical in a molecular beam. This experimental estimate did not agree with a previous theoretical result of $86.6 \mathrm{kcal} / \mathrm{mol}\left(30270 \mathrm{~cm}^{-1}\right)$ determined by Yamaguchi et al. ${ }^{6}$ from coupled-cluster $\operatorname{CCSD}(\mathrm{T})^{10-14}$ calculations with the TZ2Pf basis set. Subsequent calculations using also the coupledcluster $\operatorname{CCSD}(\mathrm{T})$ method but instead with correlation consistent basis sets ${ }^{15}$ by Le et al. ${ }^{7}$ and Sherrill et al. ${ }^{8}$ led to larger energy gaps of $87.2 \mathrm{kcal} / \mathrm{mol}\left(30500 \mathrm{~cm}^{-1}\right)$ with the aug-cc-pVTZ basis set and $88.3 \mathrm{kcal} / \mathrm{mol}\left(30900 \mathrm{~cm}^{-1}\right)$ with the energies from

\footnotetext{
† Part of the "William A. Lester, Jr., Festschrift".

* Corresponding author. E-mail: dadixon@bama.ua.edu.

$\$$ The University of Alabama.

$\S$ University of Leuven.

" Lawrence Berkeley National Laboratory and University of California, Berkeley.
}

the cc-pVnZ basis sets extrapolated to the complete basis set (CBS) limit. ${ }^{16}$ Thus, the high level theoretical results predict a singlet-triplet energy gap up to $\sim 6 \mathrm{kcal} / \mathrm{mol}$ larger than experiment.

The situation is not significantly improved for the $\Delta E_{\mathrm{S}-\mathrm{T}}$ of ethylene. The lowest-lying triplet state was identified as the $T$-state in the electronic spectrum of ethylene and described by Mulliken and co-workers. ${ }^{17,18}$ The electronic spectrum of ethylene is dominated by the $N-V\left(\pi^{*} \leftarrow \pi\right)$ singlet excitation, at $\sim 7.6 \mathrm{eV} .^{18}$ Earlier experimental studies using optical spectroscopy ${ }^{19}$ established that the excitation to the triplet $T$-state is at a much smaller energy, $4.6 \mathrm{eV}(106.1 \mathrm{kcal} / \mathrm{mol})$. Subsequent low-energy electron impact spectrometric studies (EIS) ${ }^{20-29}$ provided similar vertical excitation energies at $4.32-4.70 \mathrm{eV}$ (99.6-108.4 kcal/mol). Ion impact experiments ${ }^{30,31}$ agree with the lower end of this range giving a value of $4.3 \mathrm{eV}(99.2 \mathrm{kcal} /$ mol). More recently, Suits and co-workers ${ }^{32-34}$ studied the photodissociation reaction of ethylene sulfide $\left(\mathrm{C}_{2} \mathrm{H}_{4} \mathrm{~S}\right)$ to generate excited states of $\mathrm{C}_{2} \mathrm{H}_{4}$ and were able to identify triplet ethylene as a product. A small amount of triplet ethylene was produced near its equilibrium geometry, and from the maximum extent of the translational energy distribution, these authors ${ }^{32}$ determined the adiabatic singlet-triplet gap of ethylene $\Delta E_{\mathrm{S}-\mathrm{T}}\left(\mathrm{C}_{2} \mathrm{H}_{2}\right)$ to be $58 \pm 3 \mathrm{kcal} / \mathrm{mol}$, which yields an upper limit for the heat of formation of triplet ethylene, $\Delta H_{\mathrm{f}}=70 \pm$ $3 \mathrm{kcal} / \mathrm{mol}$.

There are extensive electronic structure calculations on the excited states of $\mathrm{C}_{2} \mathrm{H}_{4}$ going back to the earliest days of quantum chemistry. ${ }^{35-37} \mathrm{Ab}$ initio molecular orbital calculations ${ }^{38-43}$ predict that the lowest vertical triplet state should be assigned 
to the ${ }^{3} \mathrm{~B}_{1 \mathrm{u}}$ transition, although the absolute values obtained for the vertical excitation energy vary from 3.5 to $4.6 \mathrm{eV}$. Higher level calculations (CASSCF/CASPTS2) ${ }^{42}$ yield a gap of 4.39 $\mathrm{eV}$, whereas MRD-CI calculations ${ }^{43}$ gave a slightly larger value of $4.59 \mathrm{eV}\left(30700 \mathrm{~cm}^{-1}\right.$ or $\left.105.8 \mathrm{kcal} / \mathrm{mol}\right)$. Gemein and Peyerimhoff $f^{43}$ performed a theoretical study of the radiationless transition between the singlet ground and first excited triplet states of ethylene, based on a value of $T_{\mathrm{e}}=63.7 \mathrm{kcal} / \mathrm{mol}$ (without zero-point corrections) obtained at the MRD-CI/DZP level. Kim et al. ${ }^{44}$ explored several portions of the triplet $\mathrm{C}_{2} \mathrm{H}_{4}$ potential energy surface using coupled-cluster methods in their study of the $\mathrm{C}+\mathrm{CH}_{4}$ reaction. From the energies ${ }^{44}$ calculated at the $\operatorname{CCSD}(\mathrm{T}) / 6-311+\mathrm{G}(3 \mathrm{df}, 2 \mathrm{p}) / / \mathrm{QCISD} / 6-311 \mathrm{G}(\mathrm{d}, \mathrm{p})$ level, a value of $\Delta E_{\mathrm{S}-\mathrm{T}}\left(\mathrm{C}_{2} \mathrm{H}_{4}\right)=64.5 \mathrm{kcal} / \mathrm{mol}$ can be derived, including a ZPE correction of $3.2 \mathrm{kcal} / \mathrm{mol}$. Lester and coworkers ${ }^{45}$ carried out diffusion Monte Carlo (DMC) calculations on the ground state singlet and first excited triplet state of ethylene at the MP2/6-311++ $\mathrm{G}^{* *}$ geometries, with trial functions constructed from Hartree-Fock, complete active space self-consistent field, and multiconfigurational self-consistent field wavefunctions. Total atomization energies (TAEs) were calculated for the singlet and triplet states at these optimized geometries. Zero point energies were obtained by scaling the MP2/6-311++G(d,p) values by 0.97 . The vertical and adiabatic singlet-triplet gaps were predicted to be $103.5 \pm 0.3$ and 66.4 $\pm 0.3 \mathrm{kcal} / \mathrm{mol}$, respectively. The $\mathrm{DMC}$ vertical transition energy is consistent with the MRD-CI value of $105.8 \mathrm{kcal} / \mathrm{mol},{ }^{43}$ as well as the experimental EIS result of $4.36 \mathrm{eV}(100.5 \mathrm{kcal} /$ mol). ${ }^{25,26}$ No experimental error bars are reported. The DMC adiabatic energy difference between the ground state and the first exited triplet state is close to the previous $\operatorname{CCSD}(\mathrm{T})$ result ${ }^{44}$ of $64.5 \mathrm{kcal} / \mathrm{mol}$, and both are substantially larger than the experimental estimate of $58 \pm 3 \mathrm{kcal} / \mathrm{mol}^{32}$

As it is now possible to perform higher level calculations with basis sets that can be extrapolated to the complete basis set limit for such species, we have calculated the singlet-triplet gap of ethylene using current state-of-the-art electronic structure calculations. The triplet state of ethylidene, the $\mathrm{H}_{3} \mathrm{CCH}$ carbene isomer, and the 1,2-H shift pathway connecting both isomers ${ }^{46}$ were also studied. In addition, we calculated the adiabatic singlet-triplet gaps of the $\mathrm{C}_{2} \mathrm{H}_{2}$ isomers acetylene and vinylidene. Extensive investigations on thermochemical parameters ${ }^{47-49}$ including singlet - triplet splittings ${ }^{4}$ have demonstrated that the TAEs of small molecules and radicals can be predicted within $\pm 1.0 \mathrm{kcal} / \mathrm{mol}$, when coupled-cluster $\operatorname{CCSD}(\mathrm{T})$ electronic energies obtained with the correlation-consistent basis sets and extrapolated to the complete basis set limit (CBS), can be used, and other smaller corrections can be included.

\section{Computational Methods}

Electronic structure calculations were done by using the Gaussian $03^{50}$ and MOLPRO ${ }^{51}$ suites of programs. Geometry parameters of each structure were fully optimized using molecular orbital theory at the second-order perturbation theory ${ }^{52}$ MP2 and coupled-cluster theory $\operatorname{CCSD}(\mathrm{T})$ levels ${ }^{10-14}$ with the correlation-consistent aug-cc-pVTZ basis set. ${ }^{15}$ For open shell electron configurations, the fully unrestricted formalism was used for calculations done with Gaussian 03. Single-point electronic energies were also calculated using the restricted coupled-cluster R/UCCSD(T) formalism in conjunction with the correlation-consistent aug-cc-pVnZ $(n=\mathrm{D}, \mathrm{T}, \mathrm{Q}, 5)$ basis sets at the $(\mathrm{U}) \operatorname{CCSD}(\mathrm{T})$ /aug-cc-pVTZ optimized geometries. For simplicity, the basis sets are denoted hereafter as aVnZ. In the R/UCCSD(T) approach, a restricted open shell Hartree-Fock
(ROHF) calculation is initially performed and the spin constraint is relaxed in the coupled cluster calculation. ${ }^{53-55}$ The CCSD(T) energies were extrapolated to the complete basis set (CBS) limit energies using the following expressions:

$$
E(x)=A_{\mathrm{CBS}}+B \exp [-(x-1)]+C \exp \left[-(x-1)^{2}\right]
$$

where $x=2-4$ for the aVnZ basis, $\mathrm{D}, \mathrm{T}$, and $\mathrm{Q}$, respectively, and $^{56}$

$$
E(x)=E_{\mathrm{CBS}}+B / x^{3}
$$

where $x=4$ and 5 for aVQZ and aV5Z, respectively.

After the valence electronic energy, the largest contribution to the TAE is the zero-point energy (ZPE). Evaluation of the ZPEs is described below. To evaluate the TAEs, smaller corrections were also included. Core-valence corrections $\left(\Delta E_{\mathrm{CV}}\right)$ were obtained at the $\operatorname{CCSD}(\mathrm{T}) /$ cc-pwCVTZ level of theory. ${ }^{57}$ Scalar relativistic corrections $\left(\Delta E_{\mathrm{SR}}\right)$, which account for changes in the relativistic contributions to the total energies of the molecule and the constituent atoms, were included at the CI-SD (configuration interaction singles and doubles) level of theory using the cc-pVTZ basis set. $\Delta E_{\mathrm{SR}}$ is taken as the sum of the mass-velocity and 1-electron mass-velocity Darwin (MVD) terms in the Breit-Pauli Hamiltonian. ${ }^{58}$ The spin-orbit correction is $0.085 \mathrm{kcal} / \mathrm{mol}$ for $\mathrm{C}$ from the excitation energies of Moore. ${ }^{59}$ By combining our computed $\Sigma D_{0}$ values with the known heats of formation at $0 \mathrm{~K}$ for the elements $\left(\Delta H_{\mathrm{f}}^{0}(\mathrm{H})=\right.$ $51.63 \pm 0.001 \mathrm{kcal} / \mathrm{mol}$ and $\Delta H_{\mathrm{f}}^{0}(\mathrm{C})=169.98 \pm 0.1 \mathrm{kcal} /$ mol), we have derived $\Delta H_{\mathrm{f}}^{0}$ values at $0 \mathrm{~K}$ for the molecules under study in the gas phase. We obtain heats of formation at $298 \mathrm{~K}$ by following the procedures outlined by Curtiss et al. ${ }^{60}$ All other thermochemical parameters were derived form the corresponding heats of formation.

\section{Results and Discussion}

Table 1 lists the different components of the TAEs of the five $\mathrm{C}_{2} \mathrm{H}_{4}$ and four $\mathrm{C}_{2} \mathrm{H}_{2}$ structures that we studied. The $\mathrm{C}_{2} \mathrm{H}_{4}$ structures include ethylene $\mathbf{1}\left({ }^{1} \mathrm{~A}_{\mathrm{g}}\right)$, triplet twisted ethylene 2 $\left({ }^{3} \mathrm{~A}_{1}\right)$, the transition state for rotation of triplet ethylene 2 rot $\left({ }^{3} \mathrm{~B}_{2}\right)$, triplet ethylidene $3\left({ }^{3} \mathrm{~A}^{\prime \prime}\right)$, and the transition state $4\left({ }^{3} \mathrm{~A}\right)$ for the 1,2-H shift connecting triplet isomers $\mathbf{2}$ and $\mathbf{3}$. The calculated total energies and zero point energies are given as Supporting Information. Both singlet and triplet $\mathrm{C}_{2} \mathrm{H}_{2}$ isomers were studied, including acetylene $5\left({ }^{1} \Sigma^{+} \mathrm{g}\right)$, triplet cis-acetylene $6\left({ }^{3} \mathrm{~B}_{2}\right)$, vinylidene $7\left({ }^{1} \mathrm{~A}_{1}\right)$ and triplet vinylidene $8\left({ }^{3} \mathrm{~B}_{2}\right)$. Table 2 lists the calculated heats of formation of all structures considered at both 0 and $298 \mathrm{~K}$. Table 3 summarizes the vertical and adiabatic singlet-triplet gaps of ethylene obtained using different methods, whereas Table 4 gives the corresponding results for $\mathrm{C}_{2} \mathrm{H}_{2}$ isomers. The spin-contamination in the triplet electronic state of $\mathrm{C}_{2} \mathrm{H}_{4}$ is not particularly severe, as shown by the expectation values $\left\langle S^{2}\right\rangle$ of $2.010-2.057$ for the UHF wavefunctions. Similarly, the $T_{1}$ diagnostic $^{61}$ for the CCSD wavefunctions are reasonably small, ranging from 0.011 to 0.015 for the $\mathrm{C}_{2} \mathrm{H}_{4}$ structures and from 0.014 to 0.020 for the $\mathrm{C}_{2} \mathrm{H}_{2}$ isomers (Table 1).

Triplet Ethylene and Ethylidene. The ZPE of ethylene was previously estimated ${ }^{62}$ as the average of one-half the sum of the calculated harmonic frequencies and one-half the sum of the experimental fundamentals which include anharmonic corrections. For ethylene 1, the value from the experimental fundamentals is $0.5 \Sigma v_{\mathrm{i}}=30.90 \mathrm{kcal} / \mathrm{mol}$, and the value obtained from $\operatorname{CCSD}(\mathrm{T}) / \mathrm{aVTZ}$ harmonic frequencies is $0.5 \Sigma \omega_{\mathrm{i}}=31.84$ 
TABLE 1: Calculated Atomization Energies of the $\mathrm{C}_{2} \mathrm{H}_{2}$ and $\mathrm{C}_{2} \mathrm{H}_{4}$ Structures (kcal/mol)

\begin{tabular}{|c|c|c|c|c|c|c|c|c|c|}
\hline molecule & $\begin{array}{c}\text { CBS } \\
(\mathrm{DTQ})^{a}\end{array}$ & $\begin{array}{l}\text { CBS } \\
(\mathrm{Q} 5)^{b}\end{array}$ & $\Delta E_{\mathrm{ZPE}}$ & $\Delta E_{\mathrm{CV}^{c}}$ & $\Delta E_{\mathrm{SR}^{d}}$ & $\Delta E_{\mathrm{SO}}^{e}$ & $\begin{array}{c}\Sigma D_{0}(0 \mathrm{~K}) \\
(\mathrm{DTQ})\end{array}$ & $\begin{array}{c}\Sigma D_{0}(0 \mathrm{~K}) \\
(\mathrm{Q} 5)\end{array}$ & $\begin{array}{c}\mathrm{T}_{1} \\
\text { diagnostic }\end{array}$ \\
\hline $\mathrm{CH}_{2} \mathrm{CH}_{2} \mathbf{1}\left({ }^{1} \mathrm{~A}_{\mathrm{g}}\right)$ & 561.73 & 561.99 & $31.38^{f}$ & 2.06 & -0.34 & -0.17 & 531.90 & 532.16 & 0.0114 \\
\hline $\mathrm{CH}_{2} \mathrm{CH}_{2} 2\left({ }^{3} \mathrm{~A}_{1}\right)$ & 492.96 & 493.16 & $28.16^{g}$ & 1.94 & -0.37 & -0.17 & 466.20 & 466.40 & 0.0115 \\
\hline $\mathrm{CH}_{2} \mathrm{CH}_{2} \operatorname{2rot}\left({ }^{3} \mathrm{~B}_{2}\right)$ & 476.01 & & $28.06^{h}$ & 2.12 & -0.37 & -0.17 & 449.54 & & 0.0090 \\
\hline $\mathrm{CH}_{3} \mathrm{CH} 3\left({ }^{3} \mathrm{~A}^{\prime \prime}\right)$ & 487.92 & & $29.53^{h}$ & 1.83 & -0.37 & -0.17 & 459.69 & & 0.0147 \\
\hline $\mathrm{CH}(\mathrm{H}) \mathrm{CH}_{2} 4\left({ }^{3} \mathrm{~A}\right)$ & 441.28 & & $26.17^{h}$ & 1.93 & -0.36 & -0.17 & 416.51 & & 0.0154 \\
\hline $\mathrm{CHCH} 5\left({ }^{1} \Sigma_{\mathrm{g}}{ }^{+}\right)$ & 402.85 & 403.17 & $16.38^{f}$ & 2.11 & -0.29 & -0.17 & 388.13 & 388.45 & 0.0137 \\
\hline $\mathrm{CHCH} 6\left({ }^{3} \mathrm{~B}_{2}\right)$ & 312.90 & 313.02 & $16.12^{i}$ & 1.50 & -0.29 & -0.17 & 297.82 & 297.94 & 0.0166 \\
\hline $\mathrm{CCH}_{2} 7\left({ }^{1} \mathrm{~A}_{1}\right)$ & 357.78 & 358.02 & $14.53^{i}$ & 1.51 & -0.21 & -0.17 & 344.37 & 344.37 & 0.0177 \\
\hline $\mathrm{CCH}_{2} \mathbf{8}\left({ }^{3} \mathrm{~B}_{2}\right)$ & 311.16 & 311.26 & $15.46^{i}$ & 1.62 & -0.32 & -0.17 & 296.83 & 296.93 & 0.0204 \\
\hline
\end{tabular}

${ }^{a}$ From CCSD(T)/CBS energies extrapolated using eq 1 with $n=\mathrm{D}, \mathrm{T}$, and $\mathrm{Q}$ and the $\operatorname{CCSD}(\mathrm{T}) / \mathrm{aVTZ}$ optimized geometries, unless otherwise noted. ${ }^{b}$ From $\operatorname{CCSD}(\mathrm{T}) / \mathrm{CBS}$ energies extrapolated using eq 2 with $n=\mathrm{Q}$ and 5 and the $\operatorname{CCSD}(\mathrm{T}) / \mathrm{aVTZ}$ optimized geometries. ${ }^{c}$ Core/valence corrections were obtained at the CCSD(T)/cc-pwCVTZ level. ${ }^{d}$ The scalar relativistic correction (MVD) is from CISD/aVTZ calculations. ${ }^{e}$ Spin orbit atomic values taken from reference 59. ${ }^{f}$ Average between the experimental (ref 62) and the CCSD(T) values. ${ }^{g} \mathrm{CCSD}(\mathrm{T}) / \mathrm{aVTZ}$ value scaled by 0.9848 obtained from ethylene at the $\mathrm{CCSD}(\mathrm{T}) / \mathrm{aVTZ}$ level. ${ }^{h} \mathrm{MP} 2 / \mathrm{aVTZ}$ value scaled by 0.9752 obtained from ethylene at the MP2/aVTZ level. ${ }^{i} \mathrm{CCSD}(\mathrm{T}) / \mathrm{aVTZ}$ value scaled by 0.9888 obtained from acetylene at the $\operatorname{CCSD}(\mathrm{T}) / \mathrm{aVTZ}$ level.

TABLE 2: Calculated Heats of Formation for the $\mathrm{C}_{2} \mathrm{H}_{2}$ and $\mathrm{C}_{2} \mathrm{H}_{4}$ Structures (kcal/mol)

\begin{tabular}{|c|c|c|c|c|}
\hline \multirow[b]{2}{*}{ structure } & \multicolumn{2}{|c|}{$\Delta H_{\mathrm{f}}(0 \mathrm{~K})$} & \multicolumn{2}{|c|}{$\Delta H_{\mathrm{f}}(298 \mathrm{~K})$} \\
\hline & $(\mathrm{DTQ})^{a}$ & $(\mathrm{Q} 5)^{b}$ & $(\mathrm{DTQ})^{a}$ & $(\mathrm{Q} 5)^{b}$ \\
\hline $\mathrm{CH}_{2} \mathrm{CH}_{2} \mathbf{1}\left({ }^{1} \mathrm{~A}_{\mathrm{g}}\right)$ & 14.6 & 14.3 & 12.6 & 12.3 \\
\hline $\mathrm{CH}_{2} \mathrm{CH}_{2} 2\left({ }^{3} \mathrm{~A}_{1}\right)$ & 80.3 & 80.1 & 78.7 & 78.5 \\
\hline $\mathrm{CH}_{2} \mathrm{CH}_{2} \operatorname{2rot}\left({ }^{3} \mathrm{~B}_{2}\right)$ & 96.9 & & 95.1 & \\
\hline $\mathrm{CH}_{3} \mathrm{CH} 3\left({ }^{3} \mathrm{~A}^{\prime \prime}\right)$ & 86.8 & & 85.1 & \\
\hline $\mathrm{CH}(\mathrm{H}) \mathrm{CH}_{2} 4$ & 130.0 & & 128.2 & \\
\hline $\mathrm{HCCH} 5\left({ }^{1} \Sigma_{\mathrm{g}}{ }^{+}\right)$ & 55.1 & 54.8 & 55.0 & 54.7 \\
\hline $\mathrm{HCCH} 6\left({ }^{3} \mathrm{~B}_{2}\right)$ & 145.4 & 145.3 & 145.3 & 145.2 \\
\hline $\mathrm{H}_{2} \mathrm{CC} 7\left({ }^{1} \mathrm{~A}_{1}\right)$ & 98.8 & 98.6 & 99.0 & 98.8 \\
\hline $\mathrm{H}_{2} \mathrm{CC} 8\left({ }^{3} \mathrm{~B}_{2}\right)$ & 146.4 & 146.3 & 146.3 & 146.2 \\
\hline
\end{tabular}

${ }^{a}$ From $\operatorname{CCSD}(\mathrm{T}) / \mathrm{CBS}$ energies extrapolated using eq 1 with $n=$ $\mathrm{D}, \mathrm{T}$, and $\mathrm{Q}$ and the $\operatorname{CCSD}(\mathrm{T}) / \mathrm{aVTZ}$ optimized geometries, unless otherwise noted. ${ }^{b}$ From CCSD(T)/CBS energies extrapolated using eq 2 with $n=\mathrm{Q}$ and 5 and the $\operatorname{CCSD}(\mathrm{T}) / \mathrm{aVTZ}$ optimized geometries.

TABLE 3: Summary of the Calculated Vertical and Adiabatic Singlet-Triplet Gap of Ethylene $(\mathrm{kcal} / \mathrm{mol})^{a}$

\begin{tabular}{llcc}
\hline \multicolumn{1}{c}{ method } & $\begin{array}{c}\Delta E_{\mathrm{S}-\mathrm{T}} \\
\text { (vertical) }^{b} \\
\mathbf{2 v e r t - 1}\end{array}$ & $\begin{array}{c}\Delta E_{\mathrm{S}-\mathrm{T}, e} \\
\text { (adiabatic) }^{c}\end{array}$ & $\begin{array}{c}\Delta E_{\mathrm{S}-\mathrm{T}} \\
\text { (adiabatic) }^{d} \\
\mathbf{2 - 1}\end{array}$ \\
\hline present work & & & \\
CCSD(T)/aVDZ & 103.8 & 65.6 & 62.4 \\
CCSD(T)/aVTZ & 103.7 & 67.7 & 64.5 \\
CCSD(T)/aVQZ & 103.9 & 68.4 & 65.2 \\
CCSD(T)/aV5Z & 104.0 & 68.6 & 65.4 \\
CCSD(T)/CBS(1) & 104.0 & 68.8 & 65.6 \\
CCSD(T)/CBS(2) & 104.1 & 68.8 & 65.6 \\
TAE $^{e}$ & & & 65.8 \\
DMC $^{f}$ & $103.5 \pm 0.3$ & & $66.4 \pm 0.3$ \\
Experimental & $100.5^{g}$ & & $58 \pm 3^{h}$
\end{tabular}

${ }^{a}(\mathrm{U}) \mathrm{CCSD}(\mathrm{T}) / \mathrm{aVTZ}$ optimized geometries. ${ }^{b}$ Energy difference between 2 vert ${ }^{3} \mathrm{~B}_{\text {lu }}$ and $1{ }^{1} \mathrm{~A}_{\mathrm{g}}$ states at the singlet $\mathbf{1}$ geometry. ${ }^{c}$ Energy difference between $2{ }^{3} \mathrm{~A}_{1}$ and $\mathbf{1}^{1} \mathrm{~A}_{\mathrm{g}}$ without zero-point corrections. ${ }^{d}$ Energy difference between $2{ }^{3} \mathrm{~A}_{1}$ and $1{ }^{1} \mathrm{~A}_{\mathrm{g}}$ including zero-point corrections from Table $1 .{ }^{e}$ Negative difference between $2{ }^{3} \mathrm{~A}_{1}$ and $\mathbf{1}$ ${ }^{1} \mathrm{~A}_{\mathrm{g}}$ based on the calculated (Q5) atomization energies given in Table 1. ${ }^{f}$ Diffusion Monte Carlo calculations taken from ref $45 .{ }^{g}$ EIS experiment from ref $26(4.36 \mathrm{eV}) .{ }^{h}$ Experimental estimate from ref 32.

$\mathrm{kcal} / \mathrm{mol}$, giving a best estimate of ZPE $(\mathbf{1})=31.38 \mathrm{kcal} / \mathrm{mol} .^{62}$ Evaluation of the ZPEs for triplet structures is less straightforward, as no experimental information is available. Comparison of the calculated and experimental results for ethylene yields a scaling factor, obtained as the ratio of the best ZPE estimate to the calculated $0.5 \Sigma \omega_{\mathrm{i}}$ at a given level of theory. We used the scaling factor of 0.9752 derived with the calculated (U)MP2/ aVTZ frequencies for structures 2rot, 3, and 4. For the
(U)CCSD(T)/aVTZ frequencies of $\mathbf{2}$ we used a scaling factor of 0.9848 leading to $\operatorname{ZPE}(\mathbf{2})=28.16 \mathrm{kcal} / \mathrm{mol}$. We note that the difference between the ZPEs of $\mathbf{1}$ and $\mathbf{2}$ obtained at the MP2 is $3.0 \mathrm{kcal} / \mathrm{mol}$, which is close to the $\operatorname{CCSD}(\mathrm{T})$ difference of $3.2 \mathrm{kcal} / \mathrm{mol}$.

For ethylene 1, the calculated TAEs of 531.9 and $532.2 \mathrm{kcal} /$ mol with $\operatorname{CCSD}(\mathrm{T}) / \mathrm{CBS}$ energies extrapolated using eqs 1 and 2 , respectively, are essentially the same as the experimental value. ${ }^{63}$

In its singlet ground state, ethylene belongs to the $D_{2 h}$ point group and its orbital configuration is $1^{1} \mathrm{~A}_{\mathrm{g}}$ : ...( $\left(\mathrm{b}_{3 \mathrm{~g}}\right)^{2}\left(\mathrm{~b}_{3 \mathrm{u}}\right)^{2}\left(\mathrm{~b}_{2 \mathrm{~g}}\right)^{0}$. The vertical triplet state resulting from a HOMO $\rightarrow$ LUMO excitation corresponds to a configuration 2 vert ${ }^{3} \mathrm{~B}_{1 \mathrm{u}}$ : ...( $\left.\mathrm{b}_{3 \mathrm{~g}}\right)^{2}$ $\left(b_{3 u}\right)^{1}\left(b_{2 g}\right)^{1}$. As shown in Table 3 , the vertical gap computed using the $\operatorname{CCSD}(\mathrm{T})$ method is essentially independent of extension of the one-electron basis set. Thus our calculations predict a vertical excitation energy of $\Delta E_{\mathrm{S}-\mathrm{T} \text {,vert }}\left({ }^{3} \mathrm{~B}_{1 \mathrm{u}}-{ }^{-1} \mathrm{~A}_{\mathrm{g}}\right)=$ $104.1 \mathrm{kcal} / \mathrm{mol}$ for $\mathbf{1}$. This is in excellent agreement with the diffusion Monte Carlo (DMC) result of $103.5 \pm 0.3 \mathrm{kcal} / \mathrm{mol}^{45}$ but differs somewhat from the experimental value of $100.5 \mathrm{kcal} /$ mol $(4.36 \mathrm{eV})^{26}$ and the earlier CASPT2 result of $101.2 \mathrm{kcal} /$ mol $(4.39 \mathrm{eV}) .{ }^{42}$ The smaller CASPT2 value could in part be due to the use of a much smaller TZP basis set

The structural changes due to geometry relaxation from the vertical triplet position 2vert are schematically illustrated in Figure 1 using the $\operatorname{CCSD}(\mathrm{T}) / \mathrm{CBS}$ energies. Maintaining the planar $D_{2 h}$ conformation, the triplet state is stabilized by undergoing a $\mathrm{C}-\mathrm{C}$ stretch motion, reaching a value of $1.540 \AA$ (essentially a carbon-carbon single bond) at the energy minimum position $\mathbf{2}$ pl of the ${ }^{3} \mathrm{~B}_{1 \mathrm{u}}$ state. This stretch strongly stabilizes the triplet by $17.9 \mathrm{kcal} / \mathrm{mol}$, the energy difference between $\mathbf{2 v e r t}$ and $\mathbf{2 p l}$. The planar structure $\mathbf{2} \mathbf{p l}$ is characterized by three imaginary frequencies, $\mathrm{a}_{\mathrm{u}}$ at $687 \mathrm{i} \mathrm{cm} \mathrm{cm}^{-1}, \mathrm{~b}_{3 \mathrm{u}}$ at $384 \mathrm{i}$ $\mathrm{cm}^{-1}$, and $\mathrm{b}_{2 \mathrm{~g}}$ at $245 \mathrm{i} \mathrm{cm}^{-1}$, at the UMP2/aVTZ level. The imaginary vibrational modes correspond to distortions of $\mathrm{H}$-atoms in different directions. Geometry relaxation following the smallest imaginary $b_{2 g}$ mode leads to the structure 2trans, which actually has a trans-bent $C_{2 h}$ conformation $\left(a^{3} \mathrm{~B}_{\mathrm{u}}\right.$ electronic state). Such a motion is energetically negligible; the energy difference between $\mathbf{2 p l}$ and $\mathbf{2 t r a n s}$ is $0.01 \mathrm{kcal} / \mathrm{mol}$. 2trans remains characterized by two imaginary frequencies, $\mathrm{a}_{\mathrm{u}}$ at $649 \mathrm{i} \mathrm{cm}^{-1}$ and $\mathrm{b}_{\mathrm{u}}$ at $254 \mathrm{i} \mathrm{cm} \mathrm{cm}^{-1}$. Geometry relaxation of 2 trans along the smaller imaginary mode $b_{u}$ gives rise to the structure 2rot, which is $0.38 \mathrm{kcal} / \mathrm{mol}$ lower in energy than 2trans. 2rot has a ${ }^{3} \mathrm{~B}_{2}$ electronic state in $C_{2 v}$ symmetry with a cis-bent configuration and only one imaginary frequency, $\mathrm{a}_{2}$ at $681 \mathrm{i}$ 
TABLE 4: Summary of the Adiabatic Singlet-Triplet Gaps of Acetylene and Vinylidene and the Energy Difference of Singlet Isomers $(\mathrm{kcal} / \mathrm{mol})^{a}$

\begin{tabular}{|c|c|c|c|c|c|}
\hline method & $\begin{array}{c}\Delta E_{\mathrm{S}-\mathrm{T}, e} \\
\text { (adiabatic) }^{b} \\
\mathbf{6}-\mathbf{5}\end{array}$ & $\begin{array}{c}\Delta E_{\mathrm{S}-\mathrm{T}, \text { adia }} \\
\text { (adiabatic) }^{c} \\
\quad \mathbf{6}-\mathbf{5}\end{array}$ & $\begin{array}{c}\Delta E_{\mathrm{S}-\mathrm{T}, e} \\
\text { (adiabatic) }^{d} \\
\mathbf{8}-\mathbf{7}\end{array}$ & $\begin{array}{c}\Delta E_{\mathrm{S}-\mathrm{T}, \text { adia }} \\
\text { (adiabatic) }^{e} \\
\mathbf{8}-\mathbf{7}\end{array}$ & $\begin{array}{l}\Delta E^{f} \\
5-7\end{array}$ \\
\hline \multicolumn{6}{|l|}{ present work } \\
\hline $\operatorname{CCSD}(\mathrm{T}) / \mathrm{aVDZ}$ & 82.0 & 81.7 & 43.9 & 44.8 & 37.4 \\
\hline CCSD $(\mathrm{T}) / \mathrm{aVTZ}$ & 88.2 & 88.0 & 45.8 & 46.7 & 42.2 \\
\hline CCSD(T)/aVQZ & 89.4 & 89.1 & 46.3 & 47.2 & 42.9 \\
\hline $\operatorname{CCSD}(\mathrm{T}) / \mathrm{aV} 5 \mathrm{Z}$ & 89.8 & 89.5 & 46.5 & 47.5 & 43.1 \\
\hline $\operatorname{CCSD}(\mathrm{T}) / \mathrm{CBS}(1)$ & 90.0 & 89.7 & 46.6 & 47.5 & 43.2 \\
\hline $\operatorname{CCSD}(\mathrm{T}) / \mathrm{CBS}(2)$ & 90.1 & 89.9 & 46.8 & 47.7 & 43.3 \\
\hline TAE $^{g}$ & & 90.5 & & 47.7 & 43.8 \\
\hline experimental $^{h}$ & & 82.6 & & & 45.8 \\
\hline
\end{tabular}

${ }^{a}(\mathrm{U}) \mathrm{CCSD}(\mathrm{T}) / \mathrm{aVTZ}$ optimized geometries. ${ }^{b}$ Energy difference between $\mathbf{6}^{3} \mathrm{~B}_{2}$ and $5^{1} \Sigma_{\mathrm{g}}$ without zero-point corrections. ${ }^{c}$ Energy difference between $6^{3} \mathrm{~B}_{2}$ and $5^{1} \Sigma_{\mathrm{g}}{ }^{+}$including zero-point corrections from Table $1 .{ }^{d}$ Energy difference between $8^{3} \mathrm{~B}_{2}$ and $7{ }^{1} \mathrm{~A}_{1}$ without zero-point corrections. ${ }^{e}$ Energy difference between $8^{3} \mathrm{~B}_{2}$ and $7^{1} \mathrm{~A}_{1}$ including zero-point corrections from Table 1. ${ }^{f}$ Energy difference between $7^{1} \mathrm{~A}_{1}$ and $\mathbf{5}^{1} \Sigma_{\mathrm{g}}$ including zero-point corrections from Table 1. ${ }^{g}$ Energy difference based on the calculated (Q5) atomization energies given in Table 1. ${ }^{h}$ Reference 9.

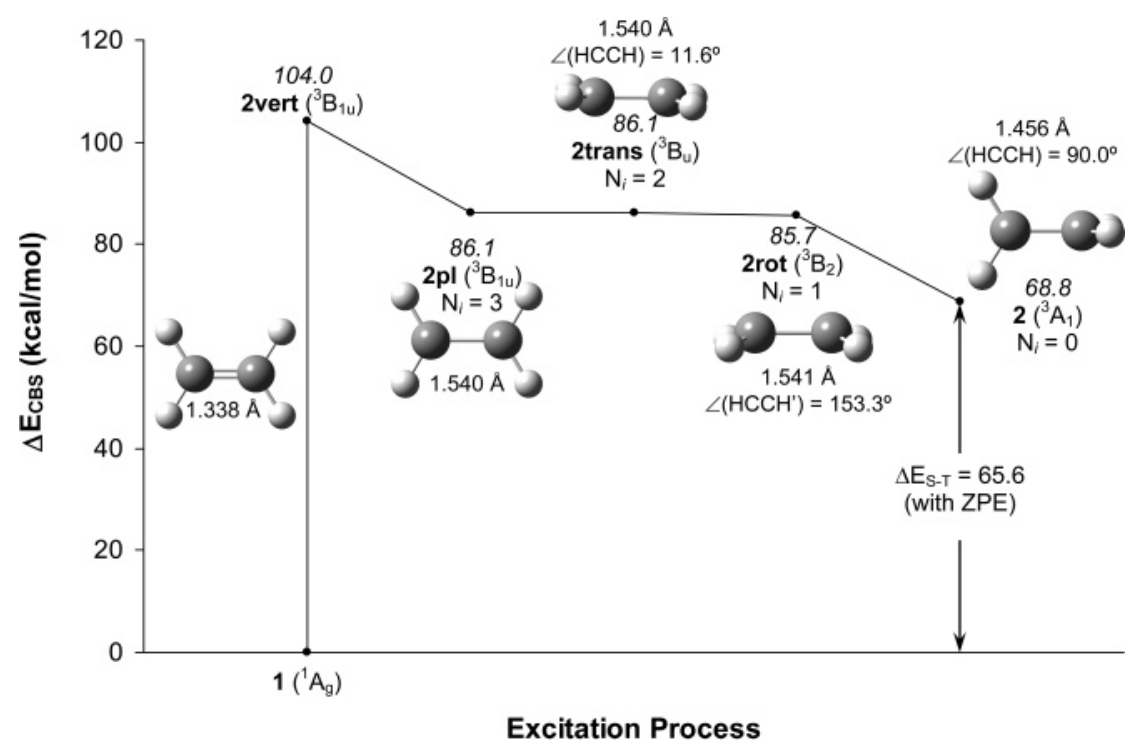

Figure 1. Illustration of the structural modification of triplet ethylene upon geometry relaxation. Geometry parameters were obtained from UCCSD(T)/aug-cc-pVTZ optimizations. In italic are relative energies obtained from UCCSD(T)/CBS total energies, with respect to ethylene 1 without zero-point corrections. $N_{\mathrm{i}}$ is the number of imaginary frequencies. $\Delta E_{\mathrm{S}-\mathrm{T}}$ is the adiabatic singlet-triplet energy gap of acetylene obtained from CBS energies and zero-point corrections. For 2trans, the $\angle(\mathrm{HCCH})$ corresponds to a cis dihedral angle; for 2 rot, the $\angle\left(\mathrm{HCCH}^{\prime}\right)$ corresponds to a trans dihedral angle.

$\mathrm{cm}^{-1}$. The rotation-distortion mode $\mathrm{a}_{2}$ makes 2 rot the transition state structure for internal rotation around the $\mathrm{C}-\mathrm{C}$ bond connecting the energy minimum triplet ethylene $\mathbf{2}$ to itself. These changes in geometry are consistent with the models for ethylene originally proposed by Mulliken and co-workers. ${ }^{18}$

The equilibrium structure of $\mathbf{2}$ has $D_{2 d}$ point group symmetry, with the two $\mathrm{CH}_{2}$ planes perpendicular to each other, and has $\mathrm{a}^{3} \mathrm{~A}_{1}$ electronic state. ${ }^{64}$ Taking the TAEs given in Table 1 , the rotational barrier of triplet ethylene, evaluated as the energy difference between 2rot and 2, is $16.7 \mathrm{kcal} / \mathrm{mol}$. This is substantially larger than the rotation barrier around a single $\mathrm{C}-\mathrm{C}$ bond in ethane of $\sim 3 \mathrm{kcal} / \mathrm{mol}^{65}$ The energy differences between 2 pl, 2trans, and 2rot are small $(\sim 0.4 \mathrm{kcal} / \mathrm{mol})$ and the differences in their ZPEs are larger (from 1 to $1.3 \mathrm{kcal} /$ mol) showing that the surface is quite flat in this region. In fact, the planar form $\mathbf{2 p l}$ becomes lower in energy after including zero-point corrections, as it has less real modes. To get values more precise than $0.3-0.5 \mathrm{kcal} / \mathrm{mol}$ would require a detailed fit of a potential energy surface, which would include anharmonic corrections. Thus, it is reasonable to consider that internal rotation of triplet ethylene simply corresponds to a rotation about the $\mathrm{C}-\mathrm{C}$ bond from the perpendicular minimum $\mathbf{2}$ to the planar structure 2 pl.
The adiabatic singlet-triplet energy gap of ethylene $\Delta E_{\mathrm{S}-\mathrm{T} \text {,adia }}\left(\mathrm{C}_{2} \mathrm{H}_{4}\right)$ is the energy difference between $\mathbf{2}$ and $\mathbf{1}$ at the respective equilibrium positions and is calculated to be 68.8 $\mathrm{kcal} / \mathrm{mol}$ without $\triangle \mathrm{ZPE}$ and $65.8 \mathrm{kcal} / \mathrm{mol}$ with $\triangle \mathrm{ZPE}$ (Table 3 ). The results given in Table 3 show that this gap increases slightly with respect to the increasing the size of the basis set. Again, our result for $\Delta E_{\mathrm{S}-\mathrm{T} \text {,adia }}\left(\mathrm{C}_{2} \mathrm{H}_{4}\right)$ is very close to that of $66.4 \pm 0.3 \mathrm{kcal} / \mathrm{mol}$ obtained from the quantum Monte Carlo calculations, ${ }^{45}$ and both differ significantly from the experimental estimate of $58 \pm 3 \mathrm{kcal} / \mathrm{mol} .{ }^{43,32,33}$ From TAE(2), the heat of formation of triplet ethylene is predicted to be $\Delta$ $H_{\mathrm{f}}^{0}\left(2,{ }^{3} \mathrm{~A}_{1}\right)=80.1 \pm 0.5$ and $78.5 \pm 0.5 \mathrm{kcal} / \mathrm{mol}$ at 0 and 298 $\mathrm{K}$, respectively. Suits and co-workers ${ }^{32}$ calculated the latter parameter at $70 \pm 3 \mathrm{kcal} / \mathrm{mol}$ from their experimental value of the gap and the heat of formation of $\mathrm{C}_{2} \mathrm{H}_{4}$.

The heat of formation of triplet methylene was determined to be $92.9 \mathrm{kcal} / \mathrm{mol}$ at $0 \mathrm{~K}$. ${ }^{4}$ Thus the $\mathrm{C}-\mathrm{C}$ bond energy of 2 to form two triplet $\mathrm{CH}_{2}$ molecules is $105.7 \mathrm{kcal} / \mathrm{mol}$. This corresponds to the simplest model of a $\mathrm{C}\left(\mathrm{sp}^{2}\right)-\mathrm{C}\left(\mathrm{sp}^{2}\right) \sigma$ bond energy where the two sp2 $\mathrm{C}$ atoms have their $\pi$-electron perpendicular to each other.

Similar to methylene $\left(\mathrm{CH}_{2}\right)$, ethylidene $\mathbf{3}$ has a triplet ground state $\left({ }^{3} \mathrm{~A}^{\prime \prime}\right.$ in $C_{s}$ symmetry, Figure 2). Singlet $\mathrm{CH}_{3} \mathrm{CH}$ does not 

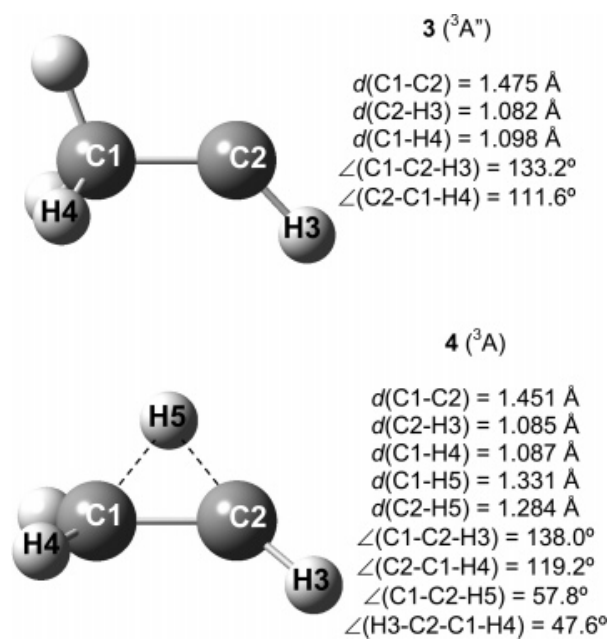

Figure 2. Selected UCCSD(T)/aug-cc-pVTZ geometrical parameters of ethylidene $3\left({ }^{3} \mathrm{~A}^{\prime \prime}\right)$ and transition state structure $4\left({ }^{3} \mathrm{~A}\right)$ for $1,2-\mathrm{H}-$ shift. Bond lengths are given in angstrom, and bond angles, in degree.

exist as an equilibrium structure but rather is a transition state for hydrogen scrambling in $\mathrm{C}_{2} \mathrm{H}_{4} \cdot{ }^{46,66}$ Our CBS results listed in Table 1 show that 3 is $6.5 \mathrm{kcal} / \mathrm{mol}$ less stable than triplet ethylene 2 , and $72.2 \mathrm{kcal} / \mathrm{mol}$ above $\mathbf{1}$, the global minimum of the $\mathrm{C}_{2} \mathrm{H}_{4}$ energy surfaces. Previous studies using coupled-cluster theory with a smaller basis $\mathrm{set}^{44}$ obtained a value of $5.8 \mathrm{kcal} /$ mol for the energy gap between $\mathbf{3}$ and $\mathbf{2}$, and placed $\mathbf{3}$ about $65.0 \mathrm{kcal} / \mathrm{mol}$ below the $\mathrm{C}\left({ }^{3} \mathrm{P}\right)+\mathrm{CH}_{4}$ limit. The heats of formation of ethylidene, $\Delta H_{\mathrm{f}}^{0}\left(\mathrm{CH}_{3} \mathrm{CH}\right)$ are 86.8 and $85.1 \mathrm{kcal} /$ $\mathrm{mol}$ at 0 and $298 \mathrm{~K}$, respectively. Thus 3 is $68.4 \mathrm{kcal} / \mathrm{mol}$ below the $\mathrm{C}\left({ }^{3} \mathrm{P}\right)+\mathrm{CH}_{4}$ limit.

On the triplet potential energy surface, the equilibrium structures $\mathbf{2}$ and $\mathbf{3}$ are linked through the transition state $\mathbf{4}$ for the 1,2-shift of hydrogen. The optimized geometry of $\mathbf{4}$ is also displayed in Figure 2. Our CBS results are in agreement with previous the previous result ${ }^{44}$ that the energy barrier for the 1,2 hydrogen shift is substantial, $43.2 \mathrm{kcal} / \mathrm{mol}$ with respect to ethylidene 3 . The heat of formation of the vinyl radical at $0 \mathrm{~K}$ has been calculated ${ }^{62}$ to be $72.6 \mathrm{kcal} / \mathrm{mol}$ in excellent agreement with the experimental value, ${ }^{67}$ which is the same. The $\mathrm{C}-\mathrm{H}$ bond energy of 2 can then be calculated to be 43.9 and 37.4 $\mathrm{kcal} / \mathrm{mol}$ in $\mathbf{3}$. Thus the transition state $\mathbf{4}$ is slightly below the $\mathrm{C}-\mathrm{H}$ bond energy of $\mathbf{2}$ but above that for $\mathbf{3}$, so it is unlikely that $\mathbf{3}$ can be isomerized to 2 without undergoing $\mathrm{C}-\mathrm{H}$ bond scission. $^{44}$

Triplet Acetylene and Vinylidene. The calculated TAEs for the $\mathrm{C}_{2} \mathrm{H}_{2}$ isomers are reported in Table 1 with heats of formation in Table 2. cis-6 corresponds to the lowest-energy form of triplet acetylene. For acetylene 5, the value from the experimental fundamentals is $0.5 \Sigma v_{\mathrm{i}}=16.19 \mathrm{kcal} / \mathrm{mol}$, and the value obtained from $\operatorname{CCSD}(\mathrm{T}) / \mathrm{aVTZ}$ harmonic frequencies is $0.5 \Sigma \omega_{\mathrm{i}}=16.56$ $\mathrm{kcal} / \mathrm{mol}$, giving a best estimate of $\mathrm{ZPE}(\mathbf{5})=16.38 \mathrm{kcal} / \mathrm{mol}$, close to the value of $16.50 \mathrm{kcal} / \mathrm{mol}$ obtained by Feller and Dixon. ${ }^{62}$ For the (U)CCSD(T)/aVTZ frequencies of structures 6 to 8 we used a scaling factor of 0.9888 .

We obtain a value of $\Delta E_{\mathrm{S}-\mathrm{T} \text {,adia }}\left(\mathrm{C}_{2} \mathrm{H}_{2}\right)=90.5 \mathrm{kcal} / \mathrm{mol}$ as the energy difference between $6\left({ }^{3} \mathrm{~B}_{2}\right)$ and 5 (Table 4), $7.7 \mathrm{kcal} /$ mol or $2693 \mathrm{~cm}^{1}$ larger than the experimental estimate by Suits and co-workers. ${ }^{8}$ Our result is consistent with that of previous calculations. ${ }^{7,8}$ The results in Table 4 clearly show that calculations with more extended one-electron functions tend to increase the singlet-triplet gap. In addition, our results confirm that the experimental singlet-triplet splitting is too low for $\mathrm{C}_{2} \mathrm{H}_{2}$.
For vinylidene, we predict $\Delta H_{\mathrm{f}}^{0}\left(\mathrm{H}_{2} \mathrm{CC}\right)=98.6$ and 98.8 $\mathrm{kcal} / \mathrm{mol}$ at 0 and $298 \mathrm{~K}$, respectively. Thus, in the singlet ground state, vinylidene is $43.7 \mathrm{kcal} / \mathrm{mol}$ less stable than its acetylene isomer. From gas phase acidity measurements, Ervin et al. ${ }^{68}$ derived heats of formation of $102.1 \pm 4.0$ and $102.2 \pm$ $4.0 \mathrm{kcal} / \mathrm{mol}$ at 0 and $298 \mathrm{~K}$, respectively. From their photodecomposition experiments, Suits et al. ${ }^{9}$ determined a value of $100.3 \pm 4 \mathrm{kcal} / \mathrm{mol}$ at $298 \mathrm{~K}$. Our calculated value is within the error bars of both sets of experiments. In the first excited triplet state, both triplet acetylene and triplet vinylidene have similar heats of formation, with triplet acetylene being $\sim 1 \mathrm{kcal} /$ mol more stable. The singlet-triplet gap for vinylidene, is $\Delta E_{\mathrm{S}-\mathrm{T} \text {,adia }}\left(\mathrm{H}_{2} \mathrm{CC}\right)=47.7 \mathrm{kcal} / \mathrm{mol}$ (Table 4).

Using $\Delta H_{\mathrm{f}, 0 \mathrm{~K}}\left(\mathrm{CH}_{2},{ }^{3} \mathrm{~B}_{1}\right)=93.4 \mathrm{kcal} / \mathrm{mol}^{4}{ }^{4} \Delta H_{\mathrm{f}, 0 \mathrm{~K}}(7)=98.7$ $\mathrm{kcal} / \mathrm{mol}$ (the average of the DTQ and Q5 values in Table 2), and $\Delta H_{\mathrm{f}, 0 \mathrm{~K}}(\mathrm{C})=169.98 \mathrm{kcal} / \mathrm{mol}$, we obtain the $\mathrm{C}-\mathrm{C}$ bond dissociation energy (BDE) of 7 as

$$
\mathrm{H}_{2} \mathrm{CC} \rightarrow \mathrm{H}_{2} \mathrm{C}+\mathrm{C} \quad \mathrm{BDE}=164.7 \mathrm{kcal} / \mathrm{mol}
$$

We can also estimate the $\mathrm{C}-\mathrm{C} \mathrm{BDE}$ of $\mathbf{3}$ by using $\Delta H_{\mathrm{f}, 0 \mathrm{~K}}(\mathbf{3})=$ $86.7 \mathrm{kcal} / \mathrm{mol}$ (Table 2), $\Delta H_{\mathrm{f}, 0 \mathrm{~K}}(\mathrm{CH})=141.6 \mathrm{kcal} / \mathrm{mol}$, and $\Delta H_{\mathrm{f}, 0 \mathrm{~K}}\left(\mathrm{CH}_{3}\right)=36.0 \mathrm{kcal} / \mathrm{mol}$ (see ref 3) as

$$
\mathrm{CH}_{3} \mathrm{CH} \rightarrow \mathrm{CH}_{3}+\mathrm{CH} \quad \mathrm{BDE}=90.9 \mathrm{kcal} / \mathrm{mol}
$$

Thus 7 has a $\mathrm{C}=\mathrm{C}$ bond strength slightly below that of $\mathrm{C}_{2} \mathrm{H}_{4}$ of $172.4 \mathrm{kcal} / \mathrm{mol}$ (taking the average for the heat of formation of $\mathrm{C}_{2} \mathrm{H}_{4}$ in Table 2) and can best be described as having a double bond with a bond length of $1.307 \AA$. The $\mathrm{C}-\mathrm{C}$ bond energy in 3 is slightly higher than that in $\mathrm{CH}_{3}-\mathrm{CH}_{3}$ of $87.9 \mathrm{kcal} / \mathrm{mol}$ (see ref 3 ) and is consistent with the bond being described as a single bond with a bond length of $1.475 \AA$.

\section{Conclusions}

The vertical and adiabatic singlet-triplet separation gaps of ethylene were evaluated to be 104.1 and $65.8 \mathrm{kcal} / \mathrm{mol}$, respectively. The adiabatic gaps of acetylene and vinylidene were determined as 90.5 and $47.7 \mathrm{kcal} / \mathrm{mol}$, respectively. The error bar of our calculated results is expected to be less than $\pm 1.0 \mathrm{kcal} / \mathrm{mol}$. Thus our calculated adiabatic singlet-triplet splittings are larger than experiment by 7.8 and $7.7 \mathrm{kcal} / \mathrm{mol}$, respectively. This difference is substantially larger than the experimental error bar of $\pm 3 \mathrm{kcal} / \mathrm{mol}$. In addition, other high accuracy computational approaches yield comparable differences from the experimental values. On the basis of the computational results, we suggest that there is a systematic overestimation of the stability of the triplet state of $\mathrm{C}_{2} \mathrm{H}_{4}$ and $\mathrm{C}_{2} \mathrm{H}_{2}$ in the photodecomposition experiments of Suits and co-workers by $7-8 \mathrm{kcal} / \mathrm{mol}$.

Acknowledgment. Funding provided in part by the Department of Energy, Office of Energy Efficiency and Renewable Energy under the Hydrogen Storage Grand Challenge, Solicitation No. DE-PS36-03GO93013. This work was done as part of the Chemical Hydrogen Storage Center. This work was supported in part by the Chemical Sciences, Geosciences and Biosciences Division, Office of Basic Energy Sciences, U.S. Department of Energy (DOE) under grant no. DE-FG0203ER15481 (catalysis center program). W.A.L. was supported by the Director, Office of Science, Office of Basic Energy Sciences, Chemical Sciences Division of the U.S. Department of Energy under Contract No. DE-AC02-05CH11231. D.A.D. is indebted to the Robert Ramsay Endowment of the University 
of Alabama. M.T.N. thanks the Flemish FWO-Vlaanderen for partly supporting his sabbatical leave at the University of Alabama.

Supporting Information Available: Total CCSD(T) energies $\left(E_{\mathrm{h}}\right)$ as a function of basis set extrapolated to the complete basis set limit and zero point energy corrections. Calculated and experimental vibrational modes (in $\mathrm{cm}^{-1}$ ) and unscaled ZPEs (in $\mathrm{kcal} / \mathrm{mol}$ ). This material is available free of charge via the Internet at http://pubs.acs.org.

\section{References and Notes}

(1) Leopold, D. G.; Murray, K. K.; Miller, A. E. S.; Lineberger, W. C. J. Chem. Phys. 1985, 83, 4849. 8625 .

(2) Ruscic, B.; Litorja, M.; Asher, R. L. J. Phys. Chem. A 1999, 103,

(3) Feller, D.; Dixon, D. A. J. Phys. Chem. A 2000, 04, 3048.

(4) Matus, M. H.; Nguyen, M. T.; Dixon, D. A. J. Phys. Chem. A 2006, 110,8864 921.

(5) Nguyen, M. T.; Ha, T. K.; Yoshimine, M. Mol. Phys. 1992, 77,

(6) Yamaguchi, Y.; Vacek, G.; Schaefer, H. F. Theor. Chim. Acta 1993, $86,97$.

(7) Le, H. T.; Flock, M.; Nguyen, M. T. J. Chem. Phys. 2000, 112, 7008 .

(8) Sherrill, C. D.; Byrd, E. F. C.; Head-Gordon, M. J. Chem. Phys. 2000, 113, 1447. 4248.

(9) Ahmed, M.; Peterka, D. S.; Suits, A. G. J. Chem. Phys. 1999, 110,

(10) Cizek, J. Adv. Chem. Phys. 1969, 14, 35.

(11) Purvis, G. D., III.; Bartlett, R. J. Chem. Phys. 1982, 76, 1910.

(12) Raghavachari, K.; Trucks, G. W.; Pople, J. A.; Head-Gordon, M. Chem. Phys. Lett. 1989, 157, 479. 8718 .

(13) Watts, J. D.; Gauss, J.; Bartlett, R. J. J. Chem. Phys. 1993, 98 ,

(14) Bartlett, R. J.; Musial, M. Rev. Mod. Phys. 2007, 79, 291.

(15) Dunning, T. H., Jr. J. Chem. Phys. 1989, 90, 1007. Kendall, R. A.; Dunning, T. H., Jr.; Harrison, R. J. J. Chem. Phys. 1992, 96, 6796.

(16) Peterson, K. A.; Woon, D. E.; Dunning, T. H., Jr. J. Chem. Phys. 1994, 100, 7410 .

(17) Wilkinson, P. G.; Mulliken, R. S. J. Chem. Phys. 1955, 23, 1895

(18) Scherer, A. J.; Mulliken, R. S. Chem. Rev. 1969, 69, 639 and references therein.

(19) Evans, D. F. J. Chem. Soc. 1960, 1735.

(20) Bowman, C. R.; Miller, W. D. J. Chem. Phys. 1965, 42, 681

(21) Doering, J. P.; Williams, A. J., III. J. Chem. Phys. 1967, 47, 4180.

(22) Brongersma, H. H. Ph.D. Thesis, University of Leiden, Leiden, The Netherlands, 1968.

(23) Trajmar, S.; Rice, J. K.; Kuppermann, A. Adv. Chem. Phys. 1970, $18,15$.

(24) Dance, D. F.; Walker, J. C. Proc. R. Soc. A 1973, 334, 259.

(25) Flicker, W. M.; Mosher, O. A.; Kuppermann, A. Chem. Phys. Lett. 1975, 36, 56.

(26) Van, Veen, E. H. Chem. Phys. Lett. 1976, 41, 540

(27) Wilden, D. G.; Comer, J. J. Phys. B 1979, 12, 371.

(28) Allan, M. Chem. Phys. Lett. 1994, 225, 156.

(29) Love, D. E. Jordan, K. D. Chem. Phys. Lett. 1995, 235, 479.

(30) More, J. H.; Doering, J. P. J. Chem. Phys. 1970, 52, 1692.

(31) More, J. H. J. Phys. Chem. 1972, 76, 1130.

(32) Qi, F.; Sorkhabi, O.; Suits, A. G. J. Chem. Phys. 2000, 112, 10707.

(33) Suits, A. G.; Qi, F. J. Electron Spectrosc. Relat. Phenom. 2001, $119,127$.

(34) Qi, F.; Sorkhabi, O.; Suits, A. G.; Chien, S. H.; Li, W. K. J. Am. Chem. Soc. 2001, 123, 148.

(35) Dunning, T.; Mckoy, V. J. Chem. Phys. 1967, 47, 1735. Shibuya, T.; McKoy, V. J. Chem. Phys. 1971, 54, 1738. Basch, H.; McKoy, V. J. Chem. Phys. 1970, 53, 1628.

(36) Dunning, T. H., Jr.; Hunt, W. J.; Goddard, W. A. Chem. Phys. Lett. 1969, 4, 147.

(37) McMurchie, L. E.; Davidson, E. R. J. Chem. Phys. 1977, 66, 2959; 1977, 67, 5613.

(38) Bunker, R. J.; Peyerimhoff, S. D.; Hsu, H. L. Chem. Phys. Lett. 1971, 11, 65 .

(39) Salem, L.; Rowland, C. Angew. Chem., Int. Ed. Engl. 1972, 11, 2.

(40) Foresman, J. B.; Head-Gordon, M.; Pople, J. A.; Frisch, M. J. J. Phys. Chem. 1992, 96, 135.
(41) Wiberg, K. B.; Hadad, C. M.; Foresman, J. B.; Chupka, W. A. Phys. Chem. 1992, 96, 10756.

(42) Serrano-Andres, L.; Merchan, M.; Nebot-Gil, I.; Lindh, R.; Roos, B. O. J. Chem. Phys. 1993, 98, 3151.

(43) Gemein, B.; Peyerimhoff, S. D. J. Phys. Chem. 1996, 110, 19257.

(44) Kim, G. S.; Nguyen, T. L.; Mebel, A. M.; Lin, S. H.; Nguyen, M. T. J. Phys. Chem. A 2003, 107, 1788.

(45) El Akramine, O.; Kollias, A. C.; Lester, W. A. J. Chem. Phys. 2003, 119, 1483.

(46) Ha, T. K.; Nguyen, M. T.; Vanquickenborne, L. G. Chem. Phys. Lett. 1982, 92, 459.

(47) Dixon, D. A.; Feller, D.; Peterson, K. A. J. Chem. Phys. 2001, $115,2576$.

(48) Dixon, D. A.; Feller, D.; Peterson, K. A. J. Phys. Chem. A 2005, 109, 4073.

(49) Matus, M. H.; Nguyen, M. T.; Dixon, D. A. J. Phys. Chem. A 2007, 111,8864 , and references therein.

(50) Frisch, M. J.; Trucks, G. W.; Schlegel,H. B.; Scuseria, G. E.; Robb, M. A.; Cheeseman, J. R.; Montgomery, J. A., Jr.; Vreven, T.; Kudin, K. N.; Burant, J. C.; Millam, J. M.; Iyengar, S. S.; Tomasi, J.; Barone, V.; Mennucci, B.; Cossi, M.; Scalmani, G.; Rega, N.; Petersson, G. A.; Nakatsuji, H.; Hada, M.; Ehara, M.; Toyota, K.; Fukuda, R.; Hasegawa, J.; Ishida, M.; Nakajima, T.; Honda, Y.; Kitao, O.; Nakai, H.; Klene, M.; Li, X.; Knox, J. E.; Hratchian, H. P.; Cross, J. B.; Bakken, V.; Adamo, C.; Jaramillo, J.; Gomperts, R.; Stratmann, R. E.; Yazyev, O.; Austin, A. J.; Cammi, R.; Pomelli, C.; Ochterski, J. W.; Ayala, P. Y.; Morokuma, K.; Voth, G. A.; Salvador, P.; Dannenberg, J. J.; Zakrzewski, V. G.; Dapprich, S.; Daniels, A. D.; Strain, M. C.; Farkas, O.; Malick, D. K.; Rabuck, A. D.; Raghavachari, K.; Foresman, J. B.; Ortiz, J. V.; Cui, Q.; Baboul, A. G.; Clifford, S.; Cioslowski, J.; Stefanov, B. B.; Liu, G.; Liashenko, A.; Piskorz, P.; Komaromi, I.; Martin, R. L.; Fox, D. J.; Keith, T.; Al-Laham, M. A.; Peng, C. Y.; Nanayakkara, A.; Challacombe, M.; Gill, P. M. W.; Johnson, B.; Chen, W.; Wong, M. W.; Gonzalez, C.; Pople, J. A. Gaussian 03, revision D.02; Gaussian, Inc.: Wallingford, CT, 2004.

(51) Werner, H.-J.; Knowles, P. J.; Amos, R. D.; Bernhardsson, A.; Berning, A.; Celani, P.; Cooper, D. L.; Deegan, M. J. O.; Dobbyn, A. J.; Eckert, F.; Hampel, C.; Hetzer, G.; Korona, T.; Lindh, R.; Lloyd, A. W.; McNicholas, S. J.; Manby, F. R.; Meyer, W.; Mura, M. E.; Nicklass, A.; Palmieri, P.; Pitzer, R. M.; Rauhut, G.; Schütz, M.; Stoll, H.; Stone, A. J.; Tarroni, R.; Thorsteinsson, T. MOLPRO-2002, a package of initio programs Universität Stüttgart, Stüttgart, Germany, and University of Birmingham, Birmingham, U.K., 2002.

(52) Pople, J. A.; Seeger, R.; Krishnan, R. Int. J. Quantum Chem. Chem. Symp. 1977, 11, 149.

(53) Rittby, M.; Bartlett, R. J. J. Phys. Chem. 1988, 92, 3033.

(54) Knowles, P. J.; Hampel, C.; Werner, H.-J. J. Chem. Phys. 1994 99,5219 . 321.

(55) Deegan, M. J. O.; Knowles, P. J. Chem. Phys. Lett. 1994, 227,

(56) Peterson, K. A.; Dunning, T. H., Jr. J. Chem. Phys. 2002, 117, 10548 Woon, D. E.; Dunning, T. H., Jr. J. Chem. Phys. 1993, 98, 1358

(57) Helgaker, T.; Klopper, W.; Koch, H.; Nagel, J. J. Chem. Phys. 1997, 106, 9639. Halkier, A.; Helgaker, T.; Jørgensen, P.; Klopper, W.; Koch, H.; Olsen, J.; Wilson, A. K. Chem. Phys. Lett. 1998, 286, 243.

(58) Davidson, E. R.; Ishikawa, Y.; Malli, G. L. Chem. Phys. Lett. 1981, $84,226$.

(59) Moore, C. E. Atomic energy levels as derived from the analysis of optical spectra; U.S. National Bureau of Standards Circular 467; U.S. Department of Commerce, National Technical Information Service, COM72-50282: Washington, DC, 1949; Volume 1, H to V.

(60) Curtiss, L. A.; Raghavachari, K.; Redfern, P. C.; Pople, J. A. J. Chem. Phys. 1997, 106, 1063.

(61) Lee, T. J.; Taylor, P. R. Int. J. Quantum Chem. 1989, S23, 199.

(62) Feller, D.; Dixon, D. A. J. Chem. Phys. 2001, 115, 3484.

(63) Chase, M. W., Jr. NIST-JANAF Tables, 4th ed. J. Phys. Chem. Ref. Data Suppl. 9, Suppl. 1 (1998). See also: Linstrom, P. J.; Mallard, W. G., Eds., NIST Chemistry WebBook; NIST Standard Reference Database Number 69; National Institute of Standards and Technology: Gaithersburg, MD, 20899, June 2005 (http://webbook.nist.gov/chemistry/).

(64) Note that in some previous papers, ${ }^{32,45}$ the electronic structure of 2 was assigned as ${ }^{3} \mathrm{~B}_{1 \mathrm{u}}$, which can cause confusion.

(65) Morokuma, K.; Umeyama, H.; Chem. Phys. Lett. 1977, 49, 333.

(66) Raghavachari, K.; Frisch, M. J.; Pople, J. A.; Schleyer, P. v. R Chem. Phys. Lett. 1982, 85, 145.

(67) Berkowitz, J.; Ellison, G. B.; Gutman, D. J. Phys. Chem. 1994, 98, 2744.

(68) Ervin, K. M.; Gronert, S.; Barlow, S. E.; Gilles, M. K.; Harrison, A. G.; Bierbaum, V. M.; DePuy, C. H.; Lineberger, W. C.; Ellision, G. B. J. Am. Chem. Soc. 1990, 112, 5750. 